Tropical Journal of Pharmaceutical Research April 2016; 15 (4): 877-883

ISSN: $1596-5996$ (print); 1596-9827 (electronic)

(C) Pharmacotherapy Group, Faculty of Pharmacy, University of Benin, Benin City, 300001 Nigeria.

All rights reserved.

Available online at http://www.tjpr.org

Original Research Article

http://dx.doi.org/10.4314/tjpr.v15i4.30

\title{
Bioequivalence evaluation of new microparticulate capsule and marketed tablet dosage forms of lornoxicam in healthy volunteers
}

\author{
Pervaiz Akhtar Shah', Sajid Bashir ${ }^{2}$, Muhammad Ahsan ${ }^{1 \star}$, Nasir Abbas ${ }^{1}$, \\ Muhammad Zubair Malik ${ }^{2}$ and Hafiz Muhammad Irfan Nazar ${ }^{1}$ \\ ${ }^{1}$ University College of Pharmacy, University of the Punjab, Lahore, Pakistan 54000, ${ }^{2}$ Faculty of Pharmacy, University of \\ Sargodha, Sargodha, Pakistan \\ *For correspondence: Email: ahsanshareef105@hotmail.com; Tel: +92 3334060054
}

Revised accepted: 20 March 2016

\begin{abstract}
Purpose: To compare oral bioavailability and pharmacokinetic parameters of different lornoxicam formulations and to assess similarity in plasma level profiles by statistical techniques.

Methods: An open-label, two-period crossover trial was followed in 24 healthy Pakistani volunteers (22 males, 2 females). Each participant received a single dose of lornoxicam controlled release (CR) microparticles and two doses (morning and evening) of conventional lornoxicam immediate release (IR) tablet formulation. The microparticles were prepared by spray drying method. The formulations were administered again in an alternate manner after a washout period of one week. Pharmacokinetic parameters were determined by Kinetica 4.0 software using plasma concentration-time data. Moreover, data were statistically analyzed at $90 \%$ confidence interval (Cl) and Schuirmann's two one-sided t-test procedure.

Results: Peak plasma concentration $\left(C_{\max }\right)$ was $20.2 \%$ lower for $C R$ formulation compared to IR formulation $\left(270.90 \mathrm{ng} / \mathrm{ml}\right.$ vs $339.44 \mathrm{ng} / \mathrm{ml}$, respectively) while time taken to attain $C_{\max }\left(t_{\max }\right)$ was 5.25 and $2.08 \mathrm{~h}$, respectively. Area under the plasma drug level versus time (AUC) curve was comparable for both $C R$ and IR formulations. The $90 \%$ confidence interval (Cl) values computed for $C_{\max }, A U C_{0-24}$, and $A \cup C_{0-\infty}$, after log transformation, were 87.21, 108.51 and $102.74 \%$, respectively, and were within predefined bioequivalence range ( $80-125 \%)$.

Conclusion: The findings suggest that $C R$ formulation of lornoxicam did not change the overall pharmacokinetic properties of lornoxicam in terms of extent and rate of lornoxicam absorption.
\end{abstract}

Keywords: Analgesic, Microparticles, Controlled release, Lornoxicam, NSAIDs, Pharmacokinetics

Tropical Journal of Pharmaceutical Research is indexed by Science Citation Index (SciSearch), Scopus, International Pharmaceutical Abstract, Chemical Abstracts, Embase, Index Copernicus, EBSCO, African Index Medicus, JournalSeek, Journal Citation Reports/Science Edition, Directory of Open Access Journals (DOAJ), African Journal Online, Bioline International, Open-J-Gate and Pharmacy Abstracts

\section{INTRODUCTION}

Lornoxicam is a short-acting non-steroidal antiinflammatory drug (NSAID) which belongs to the oxicam group. It decreases prostaglandin production by reducing cyclo-oxygenase (COX) activity. It is successfully being used in clinical settings for alleviating the symptoms of rheumatoid arthritis, osteoarthritis, acute sciatica and ankylosing spondylitis. Moreover, it has demonstrated comparable analgesic efficacy to morphine for relieving postoperative pain [3]. Due to short half-life of 3 to $5 \mathrm{~h}$, the drug is highly feasible to be formulated as controlled release formulation $[1,2]$. 
Patient compliance to prescribed regimen of NSAIDs in chronic disorders (rheumatoid arthritis \& ankylosing spondylitis) is generally poor [4]. The reasons for low compliance of NSAIDs include temporary relief of symptoms and gastric irritation associated with frequent intake of NSAIDs. Substantial variation in compliance has been observed in patients taking NSAIDs resulting in poor drug efficacy and safety [5].

Previous studies have revealed that switching from IR to $C R$ formulations reduces the side effects as well as improves outcomes of therapy [6-8]. However, no report demonstrates in-vivo comparative pharmacokinetic analysis for any NSAID drug by formulating different release formulations. Therefore, an attempt was made to compare pharmacokinetic parameters $\left(t_{\max }, \mathrm{C}_{\max }\right.$, AUC) of newly formulated CR lornoxicam microparticles with IR tablet counterpart.

\section{EXPERIMENTAL}

\section{Preparation of microparticles \\ lornoxicam-loaded}

Lornoxicam microencapsulation was achieved by spray drying according to the polymer blend concentrations specified in table 1. We dissolved weighed quantities of polymers in acetone and ethanol mixture used in the ratio of 40:60. Hydroxy propyl methyl cellulose (HPMC) $15 \mathrm{cps}$ was dissolved first in organic mixture followed by Eudragit L100 and clear solution was obtained. Then drug was added into polymer solution with continuous stirring for 45 - 60 min. Finally, drug polymer dispersion so prepared was spray-dried using Lab scale spray dryer with a nozzle of 2 $\mathrm{mm}$ diameter (YC 1500, Shangai, China). The dried particles enclosing core material were collected in the bottom of dryer [9]. The parameters set for spray drying were as follows: Inlet air temperature, $80-90^{\circ} \mathrm{C}$; inlet air volume, 200 - 300m3/h; spray rate, $8-10 \mathrm{gm} / \mathrm{min}$; product temperature, $40-50{ }^{\circ} \mathrm{C}$; and atomizing air pressure; 1 bar.

\section{Characterization of microparticles}

The formulated microcapsules were characterized for morphology, encapsulation efficiency, percent drug loading and in-vitro dissolution studies as described by Shah et al [9].

\section{Subjects' inclusion and exclusion criteria}

Twenty four healthy subjects age, $21.69 \pm 2.32$ years (range, 17.18 - 26 years); weight, $70.14 \pm$ $7.98 \mathrm{~kg}$ (range, 60.12 - $89 \mathrm{~kg}$ ); height, $180.25 \pm$ $7.32 \mathrm{~cm}$ (range, 168.2 - $190.93 \mathrm{~cm}$ ); and BMI, $21.59 \pm 2.04 \mathrm{~kg} / \mathrm{m}^{2}$ (range, $18.73-24.82 \mathrm{~kg} / \mathrm{m} 2$ ) were selected for the study. All the subjects were examined to determine their health status based on medical history, physical examination, vital signs, and laboratory tests (hematology, biochemistry, hepatic function, and urinalysis). Subjects who had a history of gastric ulcers and those receiving oral corticosteroids were not included in the study. Written informed consent was taken from each participant before the commencement of study. They were free to withdraw from the study at any time. Physical examination took into account normal laboratory tests conducted before, during and after study.

\section{Study design}

The present open label, randomized, two-way crossover, comparative bioavailability study was performed according to the principles of Helsinki Declaration (WMA) [10] and Good Clinical Practices (GCP) [11]. The study protocols were approved by the ethical committee of Human Research Review Board of University College of Pharmacy, University of the Punjab, Lahore, and the guidelines of Helsinki Declaration were followed. All the volunteers were fasted overnight at least $10 \mathrm{~h}$ prior to dosing with water as desired. Subjects received single dose of $\mathrm{CR}$ formulation and two doses of IR formulation followed by a washout period of 7 days and administration of alternate formulations.

Table 1: Formulation of microparticles by spray drying

\begin{tabular}{lcccc}
\hline $\begin{array}{l}\text { Formulation } \\
\text { code }\end{array}$ & $\begin{array}{c}\text { Drug } \\
(\mathbf{m g})\end{array}$ & $\begin{array}{c}\text { Drug : } \\
\text { polymer } \\
\text { ratio }\end{array}$ & $\begin{array}{c}\text { Eudragit L- } \\
\mathbf{1 0 0}(\mathbf{m g})\end{array}$ & $\begin{array}{c}\text { HPMC } \\
\mathbf{1 5} \mathbf{c p s} \\
\mathbf{( m g )}\end{array}$ \\
\hline AF-1 & 300 & $1: 1$ & 300 & 0 \\
AF-2 & 300 & $1: 1$ & 0 & 300 \\
AF-3 & 300 & $1: 1$ & 150 & 150 \\
AF-4 & 300 & $1: 1.5$ & 225 & 225 \\
AF-5 & 300 & $1: 2$ & 300 & 300 \\
AF-6 & 300 & $1: 2.5$ & 375 & 375 \\
AF-7 & 300 & $1: 3$ & 450 & 450 \\
\hline
\end{tabular}


Lornoxicam IR formulation was administered twice after interval of $12 \mathrm{~h}$ in each period. None of the participants was on medication of any sort which may interfere with the release and detection of drugs under study. Standard meal was provided after $4 \mathrm{~h}$ of drug administration.

\section{Blood sampling and processing}

At predetermined time interval, $5 \mathrm{ml}$ of blood was withdrawn at $0,0.5,1,2,3,5,8,10,12,13,14$, $15,18,20$ and $24 \mathrm{~h}$ by phlebotomists. Disposable $5 \mathrm{ml}$ syringes were used to collect blood samples into heparin containing centrifuge tubes. The samples, immediate after collection, were centrifuged at $4000 \mathrm{rpm}$ for $10 \mathrm{~min}$ to separate plasma which was carefully conveyed to eppendrof tubes using micropipette. The prepared plasma samples were kept at $-20{ }^{\circ} \mathrm{C}$ until lornoxicam concentration was estimated by bio-analytical HPLC method.

\section{Determination of drug in blood samples}

Lornoxicam levels in plasma samples were determined by specific and sensitive HPLC method. The mobile phase used was mixture of phosphate buffer $(\mathrm{pH} 4.5$, adjusted with orthophosphoric acid) and acetonitrile (45:55, $\mathrm{v} / \mathrm{v})$. Freshly prepared mobile phase was degassed by vacuum filtration, sonicated and pumped with a flow rate of $1 \mathrm{ml} / \mathrm{min}$. After adding $0.5 \mathrm{ml}$ of methanol, $0.5 \mathrm{ml}$ of trichloroacetic acid and $0.5 \mathrm{ml}$ of internal standard solution (piroxicam, $20 \mu \mathrm{g} / \mathrm{ml}$ ), plasma samples were vortex mixed for $3 \mathrm{~min}$ and then centrifuged at $2500 \mathrm{rpm}$ for $5 \mathrm{~min}$. Then, samples were placed on extrelut- 1 columns and dichloromethane (10 $\mathrm{ml}$ ) was used to elute lornoxicam. The eluate was dehydrated under nitrogen stream $\left(35^{\circ} \mathrm{C}\right)$ followed by reconstitution with $400 \mu$ of mobile phase. Finally, after centrifugation at 100 rpm, 50 $\mu l$ supernatant was injected into chromatographic system.

HPLC system consisted of hypersil ODS column $(150 \times 4.5$ i.d, $5 \mu \mathrm{m}$ particle size, Agilent) for carrying out separation. Class GC software was connected with variable wavelength UV detector for data processing and chromatographic integration. An isocratic pump (LC-10 ATVP, Shimadzu Corporation, Japan) was used for passing the mobile phase through the column.

\section{Tolerability assessment}

Physical assessment and vital signs (pulse rate, blood pressure and body temperature) were monitored for each enrolled subject before administration of study drugs and during the blood sampling. Subjects were continuously examined by the physicians throughout the study for incidence of adverse effects.

\section{Pharmacokinetic and statistical analyses}

The parameters included $\mathrm{C}_{\max }, \mathrm{AUC}_{0-24}, \mathrm{AUC}_{0-\infty}$, $t_{\max }$, half-life $\left(t_{1 / 2}\right)$, mean residence time (MRT), and elimination rate constant $\left(k_{e}\right)$ were determined by Kinetica 4.0 (Thermofisher Scientific, PK/PD software, USA) for each subject. $\mathrm{T}_{\max }$ and $\mathrm{C}_{\max }$ were also estimated directly from the constructed plot of plasma concentration- time profiles [12,13].

Significant difference in parameters was considered at $p<0.05$. Analysis of variance (ANOVA) for a crossover $(2 \times 2)$ study design was calculated by SPSS software (IBM Statistics 21, USA). The formulations were considered comparable if $90 \% \mathrm{Cl}$ for the geometric mean ratios (test: reference) of In-transformed $\mathrm{C}_{\max }$, $A \cup C_{0-t}$, and $A \cup C_{0-\infty}$ rest between 0.80 and 1.25 a stipulated criterion of US Food and Drug administration [14,15]. Average bioequivalence was further confirmed between test and reference formulations by applying Schuirmann two 1-sided tests [16].

\section{RESULTS}

\section{Characteristics of microparticles}

The microparticles were ellipsoidal in shape with surface morphology clearly showing presence of drug particles (Figure 1). The incorporation efficiency increased from $56.48 \% \pm 2.21$ to $83.04 \% \pm 1.22$ with the increase in the polymer contents. Percent loading was in the range of $42.88 \% \pm 1.4$ to $68.35 \% \pm 1.13$ and was independent of contents of polymer blend.

The release results showed that burst release was reduced in microparticles containing higher contents of polymers. This was due to decrease in surface associated drug. Microparticle formulations containing drug polymer blend in the ratio of $1: 1$ and $1: 1.5$ released $97.55 \pm 3.33 \%$ and $92.6 \pm 3.92 \%$ of drug, respectively at the end of $20 \mathrm{~h}$ without subsequent release. Similarly, formulation AF-6 liberated maximum drug amount of $96.16 \pm 3.88 \%$ on the time point of $20 \mathrm{~h}$. Only formulation AF-7 (1:3) sharply demonstrated drug release of $97.22 \pm 3.22 \%$ after $24 \mathrm{~h}$ that was a typical sustained release pattern. Taken together, the release pattern clearly showed that rate of drug release but not the extent was decreased on increasing amounts of polymer matrices. Out of seven formulations, 
microcapsules of one formulation (AF-7) were selected for in-vivo study based on promising results in terms of encapsulation efficiency and release studies. Moreover, the optimized formulation demonstrated near zero order kinetics.
Finally, microparticles (AF-7) equivalent to $16 \mathrm{mg}$ of lornoxicam were filled in 0 size capsules which acted as test formulation. Whilst, reference formulation was immediate release film coated tablets of lornoxicam $(8 \mathrm{mg})$. The in-vitro release profiles of test and reference formulations are shown in Figure 2.

Table 2: Physical characteristics of formulated microparticles

\begin{tabular}{lccc}
\hline Formulation & $\begin{array}{c}\text { Incorporation } \\
\text { efficiency } \\
(\%)\end{array}$ & $\begin{array}{c}\text { Drug loading } \\
\text { (\%) }\end{array}$ & $\begin{array}{c}\text { Recovery } \\
\text { (\%) }\end{array}$ \\
\hline$A F-1$ & $56.48 \pm 2.21$ & $28.25 \pm 0.2$ & $62.29 \pm 1.68$ \\
$A F-2$ & $65.52 \pm 1.68$ & $32.75 \pm 0.2$ & $53.27 \pm 2.28$ \\
$A F-3$ & $61.04 \pm 1.7$ & $30.5 \pm 0.1$ & $55.89 \pm 1.07$ \\
$A F-4$ & $68.1 \pm 1.4$ & $27.25 \pm 0.3$ & $64.16 \pm 0.92$ \\
$A F-5$ & $67.59 \pm 1.3$ & $22.5 \pm 0.4$ & $42.88 \pm 1.4$ \\
$A F-6$ & $74.27 \pm 1.15$ & $21.25 \pm 0.1$ & $59.34 \pm 1.8$ \\
$A F-7$ & $83.04 \pm 1.22$ & $20.75 \pm 0.2$ & $68.35 \pm 1.13$ \\
\hline
\end{tabular}

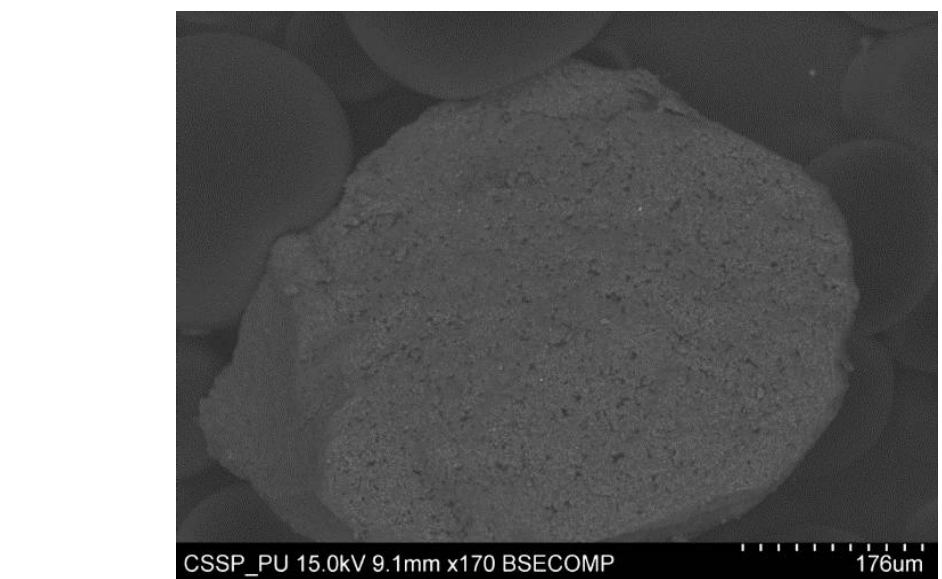

Figure 1: Scanning electron microscopy image of AF-7 microparticles

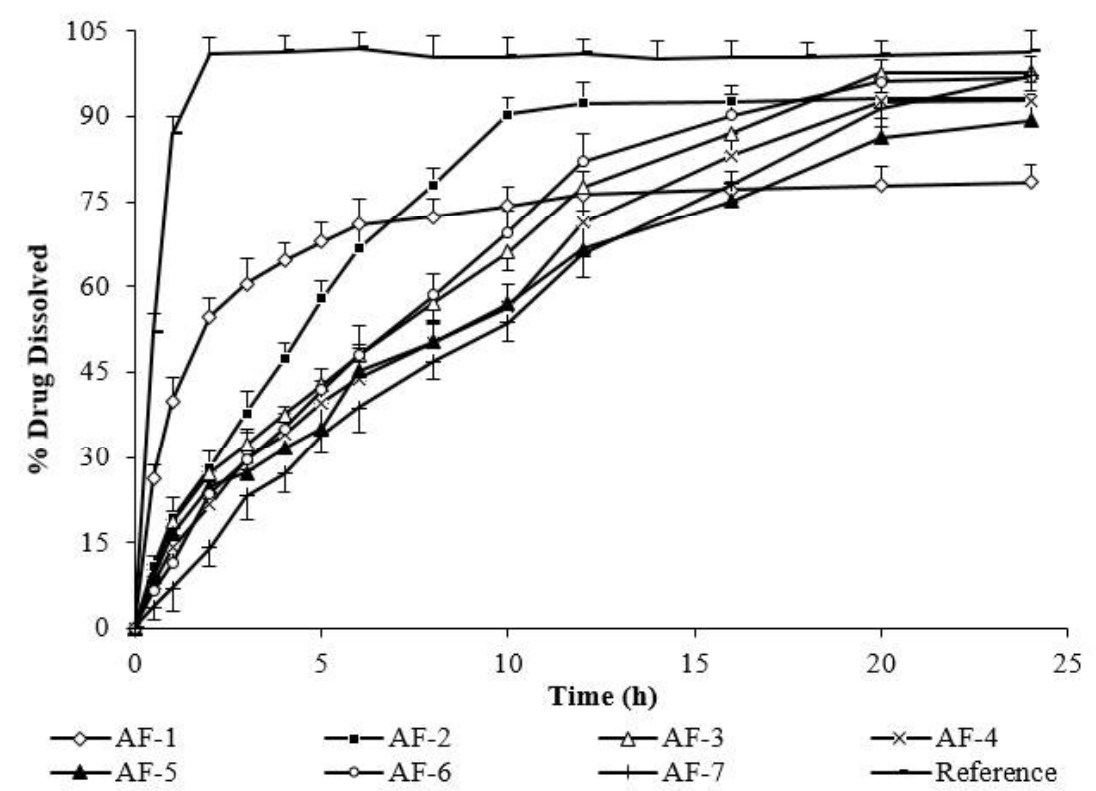

Figure 2: In-vitro release profiles of lornoxicam Reference (IR) and test (CR) formulations 
Validation parameters of developed HPLC method

Intra- and inter-day precision and recoveries (absolute and relative) of lornoxicam in human plasma are shown in Table 2.

\section{Pharmacokinetic properties}

The plasma profiles (mean \pm SD) of test and reference formulations of lornoxicam were presented in Figure 3 . The main pharmacokinetic parameters calculated were summarized in table 3. The mean $( \pm S D) C_{\max }$ values for test and reference formulations were $270.90 \pm 33 \mathrm{ng} / \mathrm{mL}$ and $339.44 \pm 41.39 \mathrm{ng} / \mathrm{mL}(p<0.05)$, respectively. The mean $\mathrm{AUC}_{0-\mathrm{t}}$ values in the test and reference formulations were $2643.03 \pm 35.03$ and $2456.62 \pm 25.39 \mathrm{ng} \cdot \mathrm{h} / \mathrm{mL}$, and the mean $\mathrm{AUC}_{0-\infty}$ were $2740.89 \pm 33.03$ and $2640.98 \pm$ $27.91 \mathrm{ng} . \mathrm{h} / \mathrm{mL}$. The median (range) $t_{\max }$ was 5.3 $(5.20 \pm 8.30)$ and $1.93(1.60-2.30)$ hours $(p<$ $0.05)$. The $k_{e}$ was $0.115(0.02)$ and $0.157(0.02)$ $\mathrm{h}^{-1}$, and the $\mathrm{t}_{1 / 2}$ was $6.13(0.86)$ and $4.46(0.45)$ hours $(p<0.05)$. ANOVA shows no effect of sequence or period on the pharmacokinetic parameters. Surprisingly, the $\mathrm{C}_{\max }$ for first dose of lornoxicam IR formulation was higher than that of second dose. This observation might relate to the influence of circadian rhythms on the kinetics of drugs leading to faster absorption in the morning compared with the evening [17].

Table 2: Validation results of lornoxicam method development (Values were mean \pm SD)

\begin{tabular}{|c|c|c|c|c|c|c|}
\hline \multirow[b]{2}{*}{$\begin{array}{l}\text { Conc. } \\
\text { spiked } \\
(\mu \mathrm{g} / \mathrm{ml})\end{array}$} & \multirow{2}{*}{$\begin{array}{c}\text { Intra-day }(\mathrm{n}=9)^{*} \\
\text { Amount } \\
\text { quantitated } \\
(\mu \mathrm{g} / \mathrm{ml})\end{array}$} & \multirow[b]{2}{*}{ RSD \% } & \multirow{2}{*}{$\begin{array}{c}\text { Inter-day }(\mathrm{n}=9)^{\star} \\
\text { Amount } \\
\text { quantitated } \\
(\mu \mathrm{g} / \mathrm{ml})\end{array}$} & \multirow[b]{2}{*}{ RSD \% } & \multicolumn{2}{|c|}{ Recovery } \\
\hline & & & & & Absolute & Relative \\
\hline 0.2 & $0.19 \pm 0.09$ & 1.5 & $0.19 \pm 0.06$ & 4.9 & $89.7 \pm 4.5$ & $96.5 \pm 5.37$ \\
\hline 3 & $2.99 \pm 0.06$ & 2.2 & $2.93 \pm 0.03$ & 2 & $98.4 \pm 3.8$ & $99.6 \pm 2.14$ \\
\hline 4 & $4.00 \pm 0.13$ & 3.5 & $3.89 \pm 0.08$ & 0.7 & $100.4 \pm 4.0$ & $100 \pm 3.1$ \\
\hline
\end{tabular}

RSD \% = relative standard deviation; *Mean of 3 concentrations and 3 replicates of each concentration, respectively

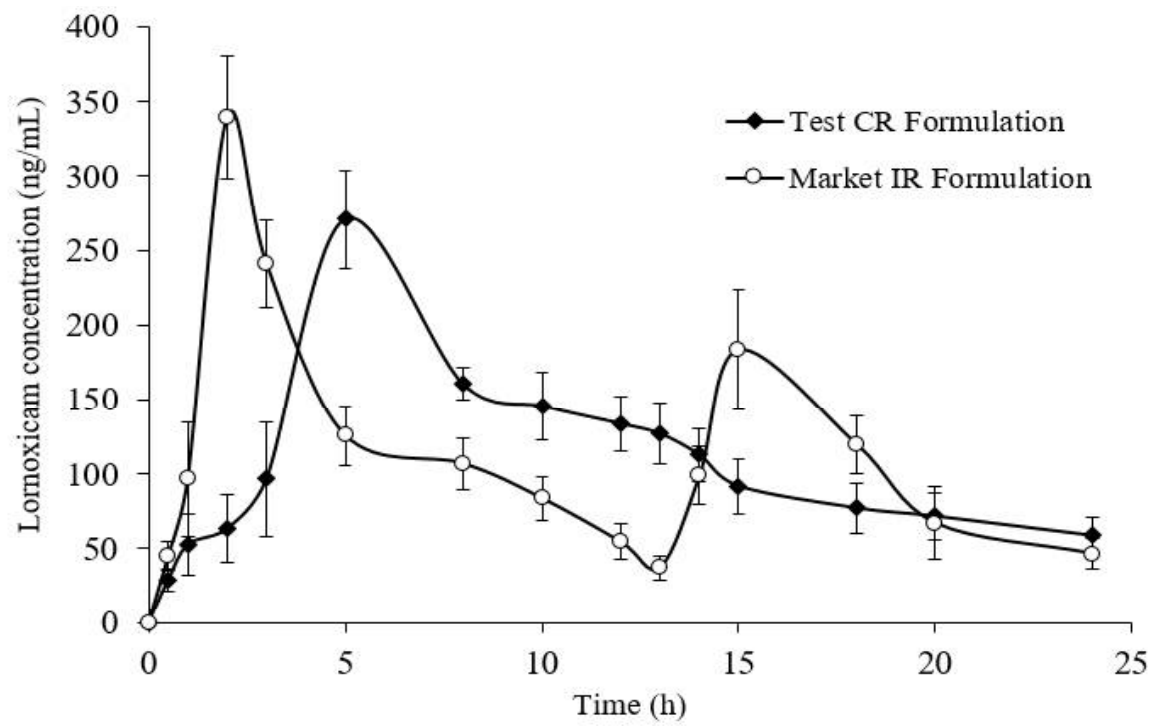

Figure 3: Plasma concentration-time profiles of test and reference formulations

Table 3: Pharmacokinetic parameters of test and reference formulations (mean \pm SD)

\begin{tabular}{lccc}
\hline Parameter & Test (CR) & Reference (IR) & P-value \\
\hline $\mathrm{C}_{\max }, \mathrm{ng} / \mathrm{ml}$ & $270.90 \pm 33$ & $339.44 \pm 41.39$ & 0.05 \\
$\mathrm{~T}_{\max }, \mathrm{h}$ & $5.25 \pm 0.87$ & $2.08 \pm 0.29$ & 0.05 \\
$\mathrm{AUC0}-24, \mathrm{ng} \cdot \mathrm{h} / \mathrm{ml}$ & $2643.03 \pm 35.03$ & $2414.5 \pm 16.37$ & $\mathrm{NS}$ \\
$\mathrm{AUC0}-\infty, \mathrm{ng} \cdot \mathrm{h} / \mathrm{ml}$ & $2756.4 \pm 29.3$ & $2682.8 \pm 21.8$ & $\mathrm{NS}$ \\
$\mathrm{t} 1 / 2, \mathrm{~h}$ & $6.13 \pm 0.86$ & $4.46 \pm 0.45$ & 0.05 \\
$\mathrm{Ke}, \mathrm{h}^{-1}$ & $0.115 \pm 0.02$ & $0.157 \pm 0.03$ & $\mathrm{NS}$ \\
$\mathrm{MRT}, \mathrm{h}$ & $14.57 \pm 1.42$ & $12.51 \pm 0.54$ & $\mathrm{NS}$ \\
\hline
\end{tabular}

'NS' means 'not significant' 
Table 4: $90 \% \mathrm{Cl}$ and ratio for test and reference formulations of Lornoxicam

\begin{tabular}{|c|c|c|}
\hline Parameter & $\begin{array}{c}\text { Test : } \\
\text { Reference } \\
\text { ratio }\end{array}$ & $90 \% \mathrm{Cl}$ \\
\hline Ln Cmax, ng/ml & 87.21 & $81.91-92.51$ \\
\hline Ln AUC0-t, ng.h/ml & 108.51 & $97.70-119.33$ \\
\hline Ln AUC $0-\infty, \mathrm{ng} . \mathrm{h} / \mathrm{ml}$ & 102.74 & $89.50-115.98$ \\
\hline
\end{tabular}

$\mathrm{Ln}=$ natural logarithm

Table 5: Schuirmann two 1-sided t-tests for comparative analysis of $\mathrm{CR}$ and IR lornoxicam formulations*

\begin{tabular}{lccc}
\hline Parameter & TL & TU & $\mathbf{t ~ ( 0 . 0 5 - 2 2 ~ d f ) ~}$ \\
\hline $\mathrm{C}_{\max }, \mathrm{ng} / \mathrm{ml}$ & 21.47 & 62.03 & 1.7171 \\
AUC0-24, $\mathrm{ng} . \mathrm{h} / \mathrm{ml}^{*}$ & 74.64 & 136.5 & 1.7171 \\
AUC $_{0-\infty}, \mathrm{ng} . \mathrm{h} / \mathrm{ml}$ & 4.88 & 142.32 & 1.7171 \\
\hline
\end{tabular}

T- t statistic; TL-lower T; TU-upper T; df-degrees of freedom; *Criteria: If $\mathrm{TL} \geq \mathrm{T}(0.05-22 \mathrm{df})$ and $\mathrm{TU} \geq \mathrm{T}$ (0.05-22 df), then bioequivalence can be deduced. If $T L \leq T(0.05-22 \mathrm{df})$ or $\mathrm{TU} \leq \mathrm{T}(0.05-22 \mathrm{df})$, then bioequivalence cannot be established between formulations

\section{Comparative pharmacokinetic profile}

The analysis of $90 \% \mathrm{Cl}$ of $\mathrm{C}_{\max }, \mathrm{AUC}_{0-\mathrm{t}}$, and $A \cup C_{0-\infty}$ values for the test and reference formulations were 81.21 to $92.51 \%, 97.70$ to $119.33 \%$, and 89.50 to $115.98 \%$, respectively and were listed in Table 4. The values were well within acceptable bioequivalence criteria (80 $125 \%$ ). The relative bioavailability of lornoxicam was $107.62 \%$. The findings of Schuirmann test also supported bioequivalence as shown in Table 5 .

\section{Tolerability}

Mild gastrointestinal problem (nausea) occurred in couple of volunteers receiving IR tablet during the second period of the study. Literature survey revealed that this mild side effect was associated with Lornoxicam salt (chlortenoxicam). The problem was immediately overcome by appropriate action of clinician and the subject successfully completed the study. CR formulation was found to lessen the side effects (nausea, diarrhea) of the salt as no active complaint was noticed from participants taking CR formulations. No other treatment related adverse event was recorded throughout the study.

\section{DISCUSSION}

This study demonstrated the bioequivalence of two oral formulations of lornoxicam - a newly developed $\mathrm{CR}$ microcapsule formulation and a marketed IR tablet - in healthy Pakistani volunteers. $\mathrm{AUC}_{0-\mathrm{t}}$ and $\mathrm{AUC}_{0-\infty}$ are indicators of total amount of absorption, $\mathrm{C}_{\max }$ reflects both extent and rate of absorption, and $t_{\max }$ shows rate of absorption and elimination [18,19]. The $\mathrm{C}_{\max }$ and $\mathrm{t}_{\max }$ of the marketed lornoxicam tablet (reference) were comparable with previous reports [20,21]. The comparable $\mathrm{C}_{\max }, \mathrm{AUC}_{0-24}$ and $\mathrm{AUC}_{0-\infty}$ for lornoxicam $\mathrm{CR}$ and IR formulations showed that both formulations had similar apparent oral clearance. As expected, it was observed that transforming the dosage forms did not change total absorption of lornoxicam even with dose administered once. Moreover, a significant drop of $20.2 \%$ in the mean value of $\mathrm{C}_{\max }$ was observed for lornoxicam CR formulation than for lornoxicam IR (270.90 \pm $33 \mathrm{ng} / \mathrm{mL}$ and $339.44 \pm 41 \mathrm{ng} / \mathrm{mL}$, respectively). This pattern clearly indicates controlled release of lornoxicam from microparticles. Furthermore, these findings proposed that, at steady state, lornoxicam $\mathrm{CR}$ and IR formulations will demonstrate comparable bioavailability when administered at the same daily dose (16 $\mathrm{mg} /$ day). A considerable difference was seen in the values of $t_{1 / 2}$ and $k_{e}$ between the test and reference formulations, further corroborating the profound effect on parameters due to modification in the formulation.

The time to reach $\mathrm{C}_{\max }\left(\mathrm{t}_{\max }\right)$ was $5.30 \mathrm{~h}$ for lornoxicam $\mathrm{CR}$ compared with $2.0 \mathrm{~h}$ for lornoxicam IR. In future, such delay in action can be avoided by incorporation of small IR fraction in microparticle dosage form. The longer elimination half-life of single CR dose compared with twice-dose of IR formulation $(6.13 \pm 0.86 \mathrm{~h}$ vs $4.46 \pm 0.45 \mathrm{~h}$, respectively) suggested that controlled release formulation is suitable for once daily dosing.

The geometric mean of lornoxicam $\mathrm{CR} /$ lornoxicam IR ratio for $\mathrm{C}_{\max }, \mathrm{AUC}_{0-\mathrm{t}}$ and $\mathrm{AUC}_{0-\infty}$ were 87.21, 108.51 and 102.74 (90\% Cls $81.91 \pm 92.51 \%, 97.7 \pm 119.3 \%$ and $89.5 \pm$ $115.98 \%$ respectively), which were within bioequivalence pre-defined range ( $80 \%-125 \%)$ with respect to total amount of lornoxicam.

The study has some limitations as the pharmacokinetic data were obtained from healthy Pakistani volunteers so the findings of the study cannot be generalized to all patient populations. Furthermore, serum concentrations of 5hydroxylornoxicam were not measured due to lack of clinical significance. Small sample size and open-label design were also study limitations. 


\section{CONCLUSION}

The findings of this non-replicated crossover study demonstrates that test lornoxicam microparticulate (CR capsules, OD) and reference (IR tablet, $\mathrm{BD}$ ) formulations at the same molar dose of $16 \mathrm{mg}$ possess comparable pharmacokinetic properties. The good controlled release properties of the microparticle formulation produced by spray drying recommend this approach for the design of oncedaily administration of the drug to achieve prolonged analgesia in chronic painful disorders.

\section{ACKNOWLEDGEMENT}

The authors are thankful to the Director, Bioequivalence Centre of University of Veterinary and Animal Sciences for financial and moral support, as well as to Ms. Wilshire Pharmaceuticals for providing facilities for HPLC analysis of plasma samples.

\section{REFERENCES}

1. Kidd B, Frenzel W. A multicenter, randomized, double blind study comparing lornoxicam with diclofenac in osteoarthritis. J Rheumatol. 1996; 23(9): 1605-1611.

2. Ahmed MO, Al-Badr AA. Lornoxicam. Profiles Drug Subst Excip Relat Methodol. 2011; 36: 205-239.

3. Rosenow DE, Albrechtsen M, Stolke D. A comparison of patient-controlled analgesia with lornoxicam versus morphine in patients undergoing lumbar disk surgery. Anesth Analg. 1998; 86(5): 1045-1050.

4. de Klerk $E$, van der Heijde $D$, Landewé $R$, van der Tempel H, Urquhart J, van der Linden S. Patient compliance in rheumatoid arthritis, polymyalgia rheumatica, and gout. J Rheumatol. 2003; 30(1): 44-54.

5. de Klerk E, Van der Linden SJ. Compliance monitoring of NSAID drug therapy in ankylosing spondylitis, experiences with an electronic monitoring device. $\mathrm{Br} \mathrm{J}$ Rheumatol. 1996; 35(1): 60-65.

6. Doughty J, Baker GA, Jacoby A, Lavaud V. Compliance and satisfaction with switching from an immediaterelease to sustained-release formulation of valproate in people with epilepsy. Epilepsy Behav. 2003; 4(6): 710716.

7. Olver JS, Burrows GD, Norman TR. The treatment of depression with different formulations of venlafaxine: a comparative analysis. Hum Psychopharmacol. 2004; 19(1): 9-16.

8. Figueroa $C$, Brecher $M$, Hamer-Maansson JE, Winter $H$. Pharmacokinetic profiles of extended release quetiapine fumarate compared with quetiapine immediate release. Prog Neuropsychopharmacol Biol Psychiatry. 2009; 33(2): 199-204.
9. Shah PA, Bashir S, Tariq I, Hafiz MA. Fabrication of Lornoxicam Loaded Eudragit L-100 Microcapsules by Spray Drying. Lat Am J Pharm. 2014; 33(5): 828-34.

10. World Medical Association Declaration of Helsinki. Ethical principles for medical research involving human subjects. [cited 2014 March 9]. Available from: http://www.wma.net/en/30publications/10policies/b3/ind ex.html.pdf.

11. European Medicines Agency. ICH Topic E 6 (R1): Guideline for Good Clinical Practice. Step 5. Note for guidance on good clinical practice (CPMP/ICH/135/95). [cited 201422 March]. Available from: http://ethikkommission.meduniwien.ac.at/fileadmin/ethik/ media/dokumente/rechtsgrundlagen/GCP.pdf.

12. Williams $R L$, Chen $M-L$, Hauck WW. Equivalence approaches. Clin Pharmacol Ther. 2002; 72(3): 229237.

13. Rowland M, Tozer TN. Clinical Pharmacokinetics: Concepts and Applications. 3rd Edition ed: Lippincott Williams \& Wilkins; 1995.

14. U.S. Department of Health and Human Services, Food and Drug Administration, Center for Drug Evaluation and Research. Guidance for Industry. Statistical Approaches to Establishing Bioequivalence. [cited 2014 Feb 2014]. Available from: http://www.fda.gov/ downloads/Drugs/GuidanceComplianceRegulatory/nfor mation/Guidances/ucm070244.pdf.

15. Bukhari NI, Zafar A, Bashir MA, Mirza AA. Bioequivalence Assessment of Two Enteric-Coated Aspirin Brands, Nu-seals $\AA$ and Loprin $\Theta$, after a Single Oral Dose of $150 \mathrm{mg}$ in Healthy Male Adults. Therapie. 2005; 60(2): 167-73.

16. Schuirmann DJ. A comparison of the two one-sided tests procedure and the power approach for assessing the equivalence of average bioavailability. $J$ Pharmacokinet Biopharm. 1987; 15(6): 657-680.

17. Baraldo $M$. The influence of circadian rhythms on the kinetics of drugs in humans. Expert Opin Drug Metab Toxicol. 2008; 4(2): 175-192.

18. Ahmad M, Pervaiz F. Comparative bioavailability and pharmacokinetics of investigational enteric-and filmcoated formulations of flurbiprofen 100-mg tablets: A single-dose, randomized, open-label, two-period, twoway crossover study in healthy Pakistani male volunteers. Clin Ther. 2010; 32(3): 607-613.

19. Wu H, Liu M, Wang S, Feng W, Yao W, Zhao H, Wei W. Pharmacokinetic properties and bioequivalence of two compound formulations of $1500 \mathrm{mg}$ ampicillin (1167 $\mathrm{mg}$ )/probenecid (333 $\mathrm{mg}$ ): A randomized-sequence, single-dose, open-label, two-period crossover study in healthy Chinese male volunteers. Clin Ther. 2010; 32(3): 597-606.

20. Balfour JA, Fitton A, Barradell LB. Lornoxicam. A review of its pharmacology and therapeutic potential in the management of painful and inflammatory conditions. Drugs. 1996; 51(4): 639-657.

21. Skjodt NM, Davies NM. Clinical pharmacokinetics of lornoxicam. Clin pharmacokinet. 1998; 34(6): 421-428 